\title{
Do Small and Medium Sized Enterprises Have Their Unique Buying Behavior Variables? - A Qualitative Approach
}

\author{
Bahtışen Kavak, Niray Tunçel, and Hüseyin Erbil Özyörük
}

\begin{abstract}
The main purpose of this study is to explore the small and medium-sized enterprises specific components of organizational buying behaviour. The study is qualitative in nature, which presents primary data collected through ten indepth interviews participants of which are selected by snowball sampling method. The results obtained from the content analysis of the interviews show that there are ten major components of small and medium-sized enterprises' organizational buying behaviour, which are product specific factors, supplier specific factors, buyer firm specific factors, economic factors, market based factors, customer based factors, relationship based factors, decision makers, information sources, and intermediaries, which show some significant differences from the ones of existing organizational buying behaviour models.
\end{abstract}

Index Terms-Buying behaviour, buying behaviour models, buying behaviour components, small and medium sized enterprises (SMEs), large companies.

\section{INTRODUCTION}

In order to be successful in b2b markets, seller firms should strive to understand the buying behaviour of the customer firms. However, buying process of the customer firms has a higher complexity which is coming from its nature of being multiphase, multi-person, multidepartmental, and multi-objective [1].

Due to the increasing need for understanding organizational buyers in depth, researchers have been focused on organizational buying process since the late 1960s. The basic three models of organizational buying behaviour are the ones developed by [2]-[4]. These earliest models of organizational buying behaviour, which attempt to identify the variables affecting the organizational buying processes, are very general and fail to be implementable to the firms in practice [1], [5] and [6]. Also, what is common for all these models is that they were actually developed concerning only the large companies not the small and medium-sized enterprises (SMEs) [7] and [8].

However, SMEs are different from large companies in terms of organizational structure [9]-[16], systems and procedures [9], organizational culture [9] and [17], human resources [16], [18]-[21] and market and customers [10],

Manuscript received September 4, 2015; revised November 3, 2015.

Bahtışen Kavak and Niray Tunçe are with the Business Administration Department of Hacettepe University, Ankara, Turkey (e-mail: bahtisenkavak@gmail.com,niraytuncel@hacettepe.edu.tr).

Hüseyin Erbil Özyörük is with the Business Administration Department of University of Turkish Aeronautical Association, Ankara, Turkey (e-mail: erbilozyoruk@hotmail.com)
[16], [22] and [23]. Therefore, large companies' buying process can be generalized neither for the whole $b 2 \mathrm{~b}$ firms [24] nor for the SMEs.

This study hence aims to explore the SME specific components of organizational buying behaviour, which are apart from the components of the existing organizational buying behaviour models within a qualitative approach. The paper firstly refers to the existing organizational buying behaviour models in literature in terms of their components. Then, the research design and method part is presented including sampling procedure and data collection process. The following section presents the content analysis of the interviews and its findings. After giving a brief conclusion of the study, the paper concludes with the contribution and limitations of the study and implications for future researches.

\section{THEORETICAL BACKGROUND}

Organizational buying behaviour has been identified with some theories and approaches. Those are buy-class theory, open system theory, consumer behaviour theory, operational approach, communication theory and reward/measurement theory.

Buy-classes theory developed by [2] considers organizational buying as a process of sequential activities Their framework has two parts: phase model and buy-class. In the phase model, "buy-phases" or stages that consist of performed sequential activities in an organizational buying case are introduced. Organizations are considered as individuals who are passing through certain stages to make a buying decision, which are problem recognition, general need description, product specification, supplier search, proposal solicitation, supplier selection, order routine specification and performance review respectively. As it is in consumer buying decision making process, these stages vary based on the effort should go into buying process depending on the buying type namely new task, modified rebuy, and straight rebuy. If it is a new task, firm passes through all these phases if it is a new task. However, for straight or modified rebuy, firms can skip some of these phases in an organizational buying case.

Additionally, [3] explain organizational buying behaviour based on the open system theory. Open system theory assumes that an organization is an open system that consists of sub-systems and is a part of larger systems all of which are mutually interacted [25]. The behaviour of each system influences and is influenced by the behaviour of other systems. Therefore, in order to understand organizational 
buying behaviour, the organizational sub-systems and the larger organizational systems should be comprehended. Based on this, [3] define the interconnected micro and macro systems that affect the buying decision of an organization. These systems are named as "influencers" and they are grouped into four main constructs, which are environment, organization, buying centre and individual participants. The environmental determinants consist of physical, technological, economic, political, legal and cultural environment. Physical and technological environment include suppliers customers and government, economic and political environment consist of labour unions, trade associations and professional groups. Finally, other business firms and other social institutions are regarded as legal and cultural environment. Moreover, the organizational determinants of buying behaviour are organizational technology (technology relevant for purchasing), organizational structure (organization of the buying centre and the purchasing function) organizational goals and tasks (buying tasks) and organizational actors (members of the buying centre). The buying centre related components are technological constraints \& technology available to the group, group structure, group tasks and member characteristics \& goals and leadership. Finally, motivation, cognitive structure, personality, learning process and perceived roles are the components related to the individual participants. According to [3], all these factors that proceed from general to specific, determine the organizational buying decision process of a firm.

Furthermore, [4] defines the organizational buying behaviour based on the theory of buyer behaviour. The theory states that the purchasing activity is determined through the effect of some external inputs on the cognitive process of an individual for a product or a service. Depending on this theory, [4] develop an organizational buyer behaviour model that is inspired from the buyer behaviour model of [26] which is a conceptual model explaining the individual buying based on the theory of buyer behaviour. According to [4], although his model is similar to the [26] model of buyer behaviour in terms of format and variable classification, there are important differences: Firstly, Howard-Sheth model may be more applicable in consumer behaviour, Sheth model is only for organizational buying. Secondly, Howard-Sheth model is restricted to the individual decision making process but Sheth model presents the joint decision making process. Sheth model consists of three distinct parts: 1 . Psychological world of the participants of the buying decisions. 2 . Conditions that trigger joint decisions among these participants. 3. Joint decision making process and the conflict among the decision makers and its resolution. Different from the two other basic models, Sheth model introduces two new constructs: information sources and conflict resolution. The information sources are described as salesmen, exhibitions and trade shows, direct mail, press releases, journal advertising, professional and technical conferences, trade news, word of mouth and others. In an organizational buying process, these information sources cause perceptual distortion and affect the expectations of the decision makers depending on the type of the information they are exposed and their participation in the active research. Moreover, according to [4], conflict become the natural consequence of the joint decision making process because of the different expectations of the individuals. However, these conflicts can be solved by problem solving, persuasion, bargaining and politicking techniques.

In addition to these three points of view, [27] and [28] bring a new approach to the organizational buying behaviour concept: operational approach. From the organizational aspect, this approach aims to integrate the concepts, principles, theory and techniques that support the actual practice of managing. Also, it contains a central core of science and technology particular to the management plus selective knowledge from other schools and approaches (for example: mathematics, psychology, industrial engineering etc.). The operational approach is only interested in the knowledge that is most relevant to the management so is not as broad as to encompass everything that may have any relationships no matter how unrelated to the managerial use [29]. Based on this approach, [27] and [28] build two more models of organizational buying behaviour and argue that the previous models of organizational buying behaviour are not operational because they are too broad, only present the conceptual structure and are not practical for the managerial use. Therefore, the models of [27] and [28] are intended to be more practical and concise for the organizational buying. The first model emphasizes the link between the characteristics of organization's buying centre and three major stages in the organizational purchasing decision process, namely elimination of alternatives, formation of decision participants' references and formation of organizational references. The model consists of four submodels; the awareness model, the acceptance model, the individual evaluation model and the group decision model, each of which describes the stages of organizational buying process. The second model of [27] and [28] comprises the four sub-models included in the first model and features market research and segmentation from the viewpoint of the seller firms. Different from the descriptive viewpoint of [3] and [4], [27] and [28] bring a practical and a more concise approach to the organizational buying behaviour theory.

Moreover, in his study, [30] integrates theory of communication with the organizational buying behaviour. His model is built on perceived risk in organizational buying process and deals with the effect of purchasing type, environmental factors and personal characteristics on risk perception in organizational buying and also the effect of risk perception on organizational buying process.

Additionally, [5] approach to organizational buying process from a psychological perspective and assume that organizational buying behaviour is a form of work behaviour. They attempt to explain the organizational buying behaviour depending on the reward/measurement theory, which is an expectancy model of motivation focusing on the reward system of the organization [31]. In this sense, their organizational buying model comprises reward and measurement systems that aim to motivate the participants of the organizational buying process [5].

The above theories and approaches contributed to the literature with the answer of three distinct questions about organizational buying behaviour: "Who participates? What happens? What causes or influences a specific decision?" 
[31]. However, the models depending on those theories are very general since they aim to define only large companies' buying behaviour, excluding small ones'. Therefore, it is still a question mark that if the existing models are implementable for [7] and [8] and resemble the buying activities of SMEs [32] which are different with their size, organizational structure, systems and procedures, organizational culture, and market and customers. Moreover, the studies on small firms' purchasing are scarce [33]. Hence, the present study recognizes the strong gap to conduct a research for describing "How do SMEs buy?" based on the open system theory.

\section{RESEARCH DESIGN AND METHOD}

From the all above, the main purpose of this research is to reveal if SMEs have their own unique buying behaviour components based on the open system theory mentioned above. For this purpose, qualitative research design is preferred. The main reason why qualitative research design is preferred is that qualitative research intends to understand and answer the questions about the meaning and experience dimensions of social world and behavior. For a good qualitative research, it is crucial to understand and radiate light upon the meanings, behaviors, actions and social contexts of the participants [34]. According to Meriam (1998), there are five types of qualitative research: basic qualitative study, phenomenology, ethnography, grounded theory and case study. Although all these types are different from each other, they bear the basic characteristics of a qualitative research [35]. In B2B marketing, qualitative case studies are frequently used to build theory [36] and this study is actually an example of one. By Miles and Huberman (1994), the term "case" is defined as "a phenomenon of some sort occurring in a bounded context. "The case is, in effect, your unit of analysis" [37]. In this research, the case is organizational buying behavior of SME's and it is the whole buying process being analyzed in depth. According to the definition of Yin (2003), a case study is "an empirical inquiry that investigates a contemporary phenomenon within its real-life context, especially when the boundaries between phenomenon and context are not clearly evident" [38]. Also Gerring (2004) argues that "for methodological purposes a case study is best defined as an in-depth study of a single unit (a relatively bounded phenomenon) where the scholar's aim is to elucidate features of a larger class of similar phenomena" [39]. Case studies are carried out in a natural atmosphere aiming to understand the nature of the current process [40], letting the researcher understand the phenomenon under investigation in a holistic approach [41], [42]. Case-based qualitative research or simply case study is the most appropriate design for this research because case studies should be used when the main purpose of the study is to answer "how" and "why" questions, the behavior of the participants cannot be manipulated, contextual conditions believed to be related to the phenomenon are being examined and there are no clear boundries between the phenomenon and the context [38]. Also just like this study, the primary objective of the case studies is to explore something unique to the cases. For this purpose, cases and/or participants with unique properties is selected and the overall aim is to find out what makes them different. In qualitative case studies, in-depth interviews are widely used to explore the unique properties of each case in detail [43]. This is the main reason for the in-depth interview technique is being used in this study. The other reasons for using this technique are that there is no potential for influences or contaminations by others, respondents find it easier to deal with the issue in a one-on-one setting, each respondent get equal time and thorough in depth, probing of each respondent is possible and also it is easier to schedule at respondents' offices [44]. Another specific reason is that the respondents wanted to meet with the researchers in their offices to ensure their privacy. Totally, 10 semi-structured in-depth interviews are conducted with the respondents who are selected through a snowball sampling method; two of them represent medium sized enterprises and the rest represents small sized ones. Moreover, the respondents consist of nine owner managers and one general manager working at Ostim Organized Industrial Region, in Ankara, Turkey.

TABLE I: GENERAL INFORMATION ABOUT THE FIRMS AND THE RESPONDENTS

\begin{tabular}{|c|c|c|c|c|}
\hline Firms & Line of Business & Number of Employees & Respondents $^{\text {a }}$ & Positions in the Firm $^{\text {Pirm A }}$ \\
\hline Printing and publishing & 45 & A & Owner Manager \\
\hline Firm B & Binding & 15 & B & Owner Manager \\
\hline Firm C & Awning manufacturing & 78 & C & Owner Manager \\
\hline Firm E & Plastic products manufacturing & 30 & D & Owner Manager \\
\hline Firm F & Metal products manufacturing & 10 & F & Owner Manager \\
\hline Firm G & $\begin{array}{c}\text { Furnaces, central heating systems, } \\
\text { compressed vessels manufacturing }\end{array}$ & 12 & G & Owner Manager \\
\hline Firm H & Restaurant & 12 & H wner Manager \\
\hline Firm I & Furniture manufacturing & 20 & I & Owner Manager \\
\hline Firm J & Candy manufacturing & 70 & J & Owner Manager \\
\hline
\end{tabular}

a. For the privacy of personal data, the names of the respondents are saved and coded with the letters from A to J.

All the interviews are carried out with the participation of the researchers at the same time. The questions are asked and the interview is managed by one researcher, while the others are recording the answers of the respondents. The interviews are conducted between the dates 18.05.2013 and
05.08.2013 and take place in the respondents' offices. The average duration of the interviews take approximately thirty minutes. Nine of the firms in our sample operate in manufacturing industry and represent a total number of nine different sectors; and one of the firms in our sample operates 
in service industry and represents the food sector. The general information about the firms and the respondents is given in Table I.

The respondents are asked the following four questions with the scenario: "Think about any significant buying decision process for a rarely purchased product at a highprice."

1) What are the factors you take into consideration?

2) Whose opinions are asked?

3) What factors affect the buying decision?

4) What factors affect your supplier choice?

These questions are augmented with some other sub questions in the course of the interviews.

First of all, all of the interview documents are revised by the researchers together. Then, the core points are collected and highlighted for each interview; each of them is reviewed by the researchers again and the highlighted issues are conceptualized. In this process it is found out that approximately fifty five components are mentioned by all respondents. Following that, a further review is conducted to analyse these components in detail in order to classify the conceptually related ones which placed in the following section.

\section{CONTENT ANALYSIS AND FINDINGS}

According to the content analysis results the major components define SMEs buying behaviour might be divided into ten groups as illustrated in Table II: product specific factors, supplier specific factors, buyer firm specific factors, economic factors, market based factors, customer based factors, relationship based factors, decision makers, information sources, and intermediaries.

TABLE II: The PROPOSEd COMPONENTS OF SMEs' ORGANiZATIONAL BUying BEHAVIOUR

\begin{tabular}{|l|l|}
\hline Product Specific Factors & $\begin{array}{l}\text { Price, Quality, Functional Features, Country of Origin, Durability, Reliability, Product Standards, Brand, } \\
\text { Seasonality, Price, Quality Certifications, Product Type (equipment, raw material etc.), Product to be New or Used }\end{array}$ \\
\hline Supplier Specific Factors & $\begin{array}{l}\text { After-Sale Services (e.g. Spare-part supplying), Payment Conditions (e.g.: payment terms), Delivery Conditions (on time } \\
\text { and on extra need), Problem-Solving Ability, Price Advantages (promotion, discount), Image, Experience, Manufacturing } \\
\text { Process, Guarantee, Honesty }\end{array}$ \\
\hline $\begin{array}{l}\text { Buyer Firm Specific } \\
\text { Factors }\end{array}$ & $\begin{array}{l}\text { Return on Investment, Current Financial Situation (e.g. budget), Compatibility of the Product with Physical Facilities, } \\
\text { Market Share of the Buyer Firm, Effect of the Purchase on Manufacturing Cost }\end{array}$ \\
\hline Economic Factors & $\begin{array}{l}\text { Exchange Rates, Economic Conditions of Buyer's Country, Economic Conditions of Supplier's Country, Economic } \\
\text { Conditions of The World }\end{array}$ \\
\hline Market Based Factors & Market Dynamics, Market Tendencies, Industry Specific Characteristics \\
\hline Customer Based Factors & Demand \\
\hline $\begin{array}{l}\text { Relationship Based } \\
\text { Factors }\end{array}$ & $\begin{array}{l}\text { Trust, Personal Relationship, Ethical Trade, Satisfaction, Loyalty, Communication Quality (eg: existing of a contact } \\
\text { person), Relationship Duration }\end{array}$ \\
\hline Decision-Makers & Owners, Shareholders, Purchasing Personnel \\
\hline Information Sources & $\begin{array}{l}\text { References (e.g. actual users of the product, other companies in the same sector), Visits (e.g. to distributors and } \\
\text { manufacturers), Employees, Internet, Trade Fairs, Second-Hand Market }\end{array}$ \\
\hline Intermediaries & Financial Intermediaries (e.g. Banks) \\
\hline
\end{tabular}

Product specific factors. The results of the interviews show that the most determinative product specific factors of the buying behaviour of the SMEs are price, quality and the functional features of the product. All of the interviewees consider them as the sine qua non components that must be considered in any buying decision process. Especially if the product is an investment like a machine that requests a specific amount of the firm capital, those components take much more attention. In addition to these components most frequently mentioned, nine more components are expressed to be important in buying behaviour: country of origin, durability and reliability of the product, product standards, brand, seasonality effect, product type, quality certification and product to be new or used.

Supplier specific factors. It is explored that the supplier specific factors are highly paid attention by the respondents. Of all, after sale service and payment conditions are mentioned as the most significant factors. Following that, delivery conditions (on time and on any extra need) and problem solving ability of the suppliers are stated as other important factors of the buying decision process. For instance, Respondent G says "If my supplier does not deliver my order on time, I will stop buying from this supplier." And also Respondent C says "If the supplier does not deliver my order on the day I requested and he promised, it causes trouble; when he delivers late, you give your final product to your customer late. It causes double trouble: to you and to your customer." Other supplier specific components mentioned by the respondents are price advantages, image, experience in industry, manufacturing process, guarantee and honesty.

Buyer firm specific factors. On the other hand there are some firm specific factors. The most important ones are the return on investment and the current financial situation of the firm. All of the respondents consider the return on investment as the most essential issue of the buying decision especially this product requires an important capital investment like a machine does. For instance, Respondent $\mathrm{F}$ says "First of all, I consider how much this machine contributes to my turnover and my production." Also, Respondent A says "If you have nothing left, how will you find money and buy. If owner's equity and capital are kept inside the firm, you can buy." Additionally, compatibility of the product with physical facilities, market share of the buyer firm and effect of purchasing on manufacturing cost are also other stated buyer firm specific components by the respondents.

Economic factors. There are also some economic factors that are considered to be important by interviewees such as exchange rate, economic conditions of buyer's country, economic conditions of supplier's country and economic conditions of the world. Among these, exchange rate and economic conditions of buyer firm's country become 
prominent. For example, Respondent A mentions that his company sometimes purchases machines from Germany; because of this, exchange rate affects the purchasing decision and if the Euro/TL parity increases much, the purchase can be cancelled or postponed. Also, Respondent B says 'Our country's and the world's economic conditions affect us when we buy a high-price product and if we have to pay it in dollars or euros",

Market-based factors. The other group of components, market-based factors suggested by respondents is market dynamics, market tendencies and industry-specific characteristics. For instance, Respondent F says "Market dynamics, market tendencies; to which direction the market will evolve... For example, for us, business will move to the laser machines so we are thinking of increasing the number of laser machines we possess. Actually, we already began buying those machines slowly"

Customer-based factors. According to the respondents, customer demand is also an important determiner of the organizational buying process; especially when the product is specialized for a production and has a high monetary value. For instance Respondent $\mathrm{H}$ says "I hate one of my suppliers, which is very well known global company but I still purchase from this company because my customers demand this brand and refuse the alternative ones so I have to... If I had chance, I would even not let them (that supplier) in my restaurant!",

Relationship-based factors. According to the respondents, one of the main aspects of the organizational buying process is the relationship between the supplier and the buyer. Among all the factors listed in this sub- group trust to the supplier comes forward. All the respondents of the study take trust as a key of the relationship. Additionally some of them mention that they develop personal relationships rather than business in time and see this as important as the business-related issues. For example, Respondent B says "Willingly or unwillingly, friendships develop between us and the supplier in time and this strengthens the trade." Ethical trade is another important buying decision criterion. For instance, Respondent D says "Ethical trade is really essential for me. One of my suppliers sent me a lower quality product than I requested but he didn't accept it first and after he accepted, he changed the product with even a lower quality than the first one he sent. After this, I never ever get in any business relationship with this company." Besides these factors, satisfaction, loyalty, communication quality and relationship duration are considered to be significant in organizational buying process.

Decision-Makers. As decision-making is considered, the most influential actors of the process are owners of the firms and shareholders respectively because SMEs are dependent on owners on many aspects, especially on the financial issues. Very few of them, only one firm in our sample employ a professional general manager who is responsible and authorized to purchase and not a shareholder of the company.

Information sources. Also, some information sources are investigated in detail during the organizational buying process of the SMEs according to the respondents. The most benefited information source is reference. All of the respondents mention that they refer to the opinions of the actual users of the product and the managers of other companies in same industry. Additionally, a visit to distributors and manufacturers in order to see the product to be purchased is stated to be a very usable information source. Moreover, some of the respondents ask for the opinions of their employees who are anyway related to purchasing of the product. For example Respondent $\mathbf{J}$ says "We get the opinions of our food engineers and foremen". Besides, Respondent C says "For example, if we buy welding machine, we get the opinions of the user of this product. If we buy an oven, we ask our cook. I want a product, which she can use easily." Furthermore, internet, trade fairs and second hand markets are also considered as important sources of information affecting organizational buyer behavior.

Intermediaries. Intermediaries also play an active role in determining buying behavior. Respondent $\mathrm{D}$ focuses on the intermediaries; he mentions that he plans his high monetary valued purchases according to the credits his bank offers him. Before giving any important buying decision, he says that he contacts with his bank and learns the credit availability for his company.

\section{DISCUSSION AND CONCLUSION}

In this study, we explored the major components of the SMEs' organizational buying behaviour, that there are differences between these components and the ones of the existing organizational buying behaviour models in literature that are generated considering the large companies. Also, we found out that these differences arise from the specific characteristics of the SMEs.

The results of this study show that there are ten major components of SMEs' organizational buying behaviour which are product specific factors, supplier specific factors, buyer firm specific factors, economic factors, market based factors, customer based factors, relationship based factors, decision makers, information sources, and intermediaries. The number of major buying behaviour components of the SMEs is less than the number of major buying behaviour components in the existing organizational buying behaviour models (for example: [3] and [4]). It might be because SMEs are working in a smaller environment and they could manage a narrower market, and thus small number of influencers.

This study also indicates that, of the environmental factors (physical, technological, economic, political, legal, and cultural) presented in the model of [3], only the economic factors are considered to be effective on the SMEs' organizational buying behaviour. We think that because SMEs have limited financial sources and an important purchase is costly and risky, economic factors, mentioned as exchange rates, economic conditions of the buyer firm's and supplier firm's country, emerge as important issues for SMEs' organizational buying behaviour.

Another interesting result is that while characteristics of the individual participants (for example: roles, expectations, personality, backgrounds, criteria) are effective on purchasing decision in existing organizational buying behaviour models (e.g. [3] and [4]), they do not emerge among the components explored in this study. Moreover, in 
contrast to the reward/measurement model of organizational buying behaviour suggested by [5], in this study it is explored that no reward/measurement system is applied to the organizational buying process of SMEs. The reason might be, in SMEs, usually, there is not a separated purchasing department where professional purchasing personnel is employed and the important purchasing decisions are mostly given by the owner managers. Thus, there is no need to motivate purchasing process participants. Even if they employ purchasing staff, there is not a measurement/reward system related to the purchasing behaviour to motivate them. Additionally, it can be said that SME owners or managers do not approach to the purchasing process from a psychological perspective so they do not mention anything related to the motivation of the purchasing participants.

Finally, different from the existing organizational buying behaviour models, in this study relationship based factors come out as a significant component of the SMEs' organizational purchasing behaviour. When SMEs give an important purchasing decision, relationship related factors such as trust, loyalty, communication quality, relationship duration become really significant for the decision makers. As [45] find that small buyers can develop long-term relationships with their respective suppliers, the result of this study also shows that the relationship with a particular supplier tends to be trustworthy, strong and long-term in which SMEs become loyal to that supplier. Also, SMEsupplier relationship is likely to be both commercial and personal. Thus, SMEs tend to sustain this relationship and primarily prefer this supplier for an important organizational purchase case.

To sum up, this study explored the components of SMEs' organizational buying behaviour and shows that due to some SME specific characteristics; these components differ in some aspects from the components of the existing organizational buying behaviour models that are suggested considering the large companies. Differences between the SMEs' organizational behavior and large companies' organizational behavior are summarized below in Table III.

TABLE III: THE COMPONENTS OF ORGANIZATIONAL BUYING BEHAVIOUR

\begin{tabular}{|ll|ll|}
\hline \multicolumn{2}{|c|}{ SMEs' Organizational Buying Behavior } & \multicolumn{1}{c|}{ Large Companies' Organizational Buying Behavior } \\
\hline$\bullet$ & Relatively small number of buying behavior components & $\bullet$ & Relatively large number of buying behavior components \\
\hline$\bullet$ & None & $\bullet \quad$ Physical, technological factor, political, legal factors and cultural factors [3] \\
\hline$\bullet$ & Characteristics of individual participants & $\bullet$ & Characteristics of individual participants [3], [4], [27], [28] \\
\hline$\bullet$ & None & $\bullet$ & Reward/measurement system [5] \\
\hline$\bullet$ & $\begin{array}{l}\text { Supplier-company relationship based factors (e.g. trust, } \\
\text { loyalty, communication quality) }\end{array}$ & $\bullet$ None \\
\hline
\end{tabular}

As stated in Table III, SME's have some buying behavior components which are special to them. So, professional marketers in the field should take these into account during their planning and implementation process when they are targeting SME's. For example, supplier-company relationship based factors such as trust, loyalty, communication quality come into prominence during SME's organizational purchasing process. This may lead companies and marketing professionals to shape their marketing mix for SME's different from large companies, for example they may place more importance on promotion tools such as personal selling. So, companies targeting both SME's and large companies may adapt their plans and practices by considering the differences mentioned in Table III.

\section{CONTRIBUTION OF THE STUdY}

In industrial marketing literature, organizational buying behaviour concept is analysed only in the frame of large companies and it is usually assumed that buying practices of the large companies is also appropriate for the SMEs. However, SMEs are different from large companies and should be studied separately. Therefore, this study is considered to be important in terms of taking attention to the unique buying behaviour of the SMEs, exploring the SME specific components of an important organizational buying.

\section{LIMITATIONS OF THE STUDY}

The research design of this study exploratory in nature and our sample consists of ten respondents. The results reflect the current thoughts and point of views of the respondents that cannot be generalized and validated for the main population that comprises all SMEs operating in Turkey. Moreover, even if the in-depths are conducted in nine different sectors, the respondents are all from Ankara. If in-depths were conducted in different cities, the results would change. Thus, the results can be stated as reliable for the analysed SMEs in Ankara for the current situation.

\section{IMPLICATIONS FOR FUTURE RESEARCHES}

This study can be carried out to a broader sample that can consist of the managers of SMEs from different sectors, cities and countries. Besides, this study aims to explore the components of the buying behaviour of the SMEs: however, by adding some extra questions like "How does an organizational buying process happen in your company?," "What do you do in this process respectively?," a buying behaviour model can be attempted to develop for SMEs. Therefore, the results of this study can provide a base and a starting point for buying process model building studies for SMEs. By increasing the number of the in-depths, the data can be diversified and used as a secondary source for a quantitative research design conducted for a similar subject. The results of this study also can be used for a development of buying behaviour scale for SMEs.

\section{REFERENCES}

[1] W. J. Johnston and J. E. Lewin, "Organizational buying behaviour: toward an integrative framework," Journal of Business Research, vol 35 , no. 1 , pp. $1-15,1996$ 
[2] P. J. Robinson, C. W. Faris, and Y. Wind, Industrial Buying and Creative Marketing, Boston: Allyn \& Bacon, 1967.

[3] F. E. Webster and Y. Wind, "A general model for understanding organizational buying behavior," The Journal of Marketing, vol. 36, no. 2, pp. 12-19, 1972.

[4] J. N. Sheth, "A model of industrial buyer behavior," The Journal of Marketing, vol. 37, no. 4, pp. 50-56, 1973.

[5] P. F. Anderson and T. M. Chambers, "A reward/measurement model of organizational buying behavior," The Journal of Marketing, vol. 49, no. 2, pp. 7-23, 1985 .

[6] D. H. McQuiston, "Novelty, complexity, and importance as causal determinants of industrial buyer behavior," The Journal of Marketing, vol. 53, no. 2, pp. 66-79, 1989 .

[7] E. S. Özmen, M. A. Öner, and F. Khosrowshahi, "How to form the knowledge that marketers need? An approach for marketers to SMEs," Business Management and Strategy, vol. 3, no. 1, pp. 61-71, 2012.

[8] E. S. Özmen, M. A. Öner, F. Khosrowshahi, and J. Underwood, "SME buying behaviour: literature review and an application agenda," The Marketing Review, vol. 13, no. 2, pp. 207-227, 2013.

[9] D. Baba, M. Yusof, S. R. Azhari, and M. Salleh, "A benchmarking implementation framework for automotive manufacturing SMEs," Benchmarking: An International Journal, vol. 13, no. 4, pp. 396-430, 2006.

[10] S. Dutta and P. Evrard, "Information technology and organization within European small enterprises," European Management Journal, vol. 17, no. 3, pp. 239-251, 1999.

[11] A. Gilmore and D. Carson, "Entrepreneurial marketing by networking," New England Journal of Entrepreneurship, vol. 2, no. 2, pp. 31-38, 1999.

[12] F. Kelliher and J. B. Henderson, "A learning framework for the small business environment," Journal of European Industrial Training, vol. 30 , no. 7, pp. 512-528, 2006.

[13] P. Kraipornsak. (2002). The plastic industry of Thailand. [Online]. Available http://www.econ.chula.ac.th/public/members/paitoon_k/Thailand.pdf

[14] P. Palvia, D. B. Means, and W. M. Jackson, "Determinants of computing in very small business," Information \& Management, vol. 27, no. 3, pp. 161-167, 1994.

[15] P. Raju, S. C. Lonial, and M. D. Crum, "Market orientation in the context of SMEs: A conceptual framework," Journal of Business Research, vol. 64, no. 12, pp. 1320-1326, 2011.

[16] B. Simpson, "Innovation and the micro-enterprise," International Journal of Services Technology and Management, vol. 2, no. 3/4, pp 377-387, 2001.

[17] T. Müftüoğlu, Türkiye'de Küçük ve Orta Ölçekli Issletmeler KOBİ'ler, Ankara: Turhan Kitabevi Yayınları, 2007.

[18] A. E. Barber, M. J. Wesson, Q. M. Roberson, and M. S. Taylor, "A tale of two job markets: organizational size and its effects on hiring practices and job search behavior," Personnel Psychology, vol. 52, no. 4, pp. 841-867, 1999.

[19] M. S. Cardon and C. E. Stevens, "Managing human resources in small organizations: what do we know?" Human Resource Management Review, vol. 14, no. 3, pp. 295-323, 2004

[20] J. Curran, "Training and research strategies for small firms," Journal of General Management, vol. 13, no. 3, pp. 24-37, 1988

[21] I. O Williamson, D. M. Cable, and H. E. Aldrich, "Smaller but not necessarily weaker: How small businesses can overcome barriers to recruitment," Managing People in Entrepreneurial Organizations: Learning from the Merger of Entrepreneurship and Human Resource Management, pp. 83-106, 2002.

[22] F. B. Krake, "Successful brand management in SMEs: A new theory and practical hints," Journal of Product \& Brand Management, vol. 14, no. 4, pp. 228-238, 2005.

[23] D. Storey and R. Cressy, "Small business risk: A firm bank perspective," Working Paper: The Centre for Small and Medium Sized Enterprises (CSME), Warwick Business School, Coventry 39, pp. 1-16, 1996.

[24] P. Rauyruen, K. E. Miller, and N. J. Barrett, "Relationship quality as a predictor of B2B customer loyalty," Journal of Business Research, vol. 60 , no. 1 , pp. 21-31, 2007.

[25] D. Katz and R. L. Kahn, The Social Psychology of Organizations, 2nd edition, New York: Wiley, 1978.

[26] J. A. Howard and J. N. Sheth, The Theory of Buyer Behaviour, New York: Wiley, 1969.

[27] J. M. Choffray and G. L. Lilien, "Assessing response to industrial marketing strategy," The Journal of Marketing, vol. 42, no. 2, pp. 2031, 1978.
[28] J. M. Choffray and G. L. Lilien, "Industrial market segmentation by the structure of the purchasing process," Industrial Marketing Management, vol. 9, no. 4, pp. 331-342, 1980.

[29] H. Koontz, "The management theory jungle revisited," Academy of Management Review, vol. 5, no. 2, pp. 175-188, 1980.

[30] J. Newall, "Industrial buyer behaviour: A model of the implications of risk handling behaviour for communication policies in industrial marketing," European Journal of Marketing, vol. 11, no. 3, pp. 166$211,1977$.

[31] J. F. Tanner, "Organizational buying theories: A bridge to relationships theory," Industrial Marketing Management, vol. 28, no. 3, pp. 245-255, 1999.

[32] A. Viljamaa, "Exploring small manufacturing firms' process of accessing external expertise," International Small Business Journal, vol. 29 , no. 5 , pp. $472-488,2011$

[33] W. J. Morrissey and L. Pittaway, "Buyer-supplier relationships in small firms," International Small Business Journal, vol. 24, no. 3, pp. 272-298, 2006.

[34] E. Fossey, C. Harvey, F. McDermott, and L. Davidson, "Understanding and evaluating qualitative research," Australian and New Zealand Journal of Psychiatry, vol. 36, pp. 717-732, 2002.

[35] S. B. Merriam, Qualitative Research and Case Study Applications in Education, San Francisco: Jossey-Bass Publishers

[36] A. Dubois and L. Araujo, "Case research in purchasing and supply management: Opportunities and challenges," Journal of Purchasing \& Supply Management, vol. 13, no. 3, pp. 170-181, 2007.

[37] M. B. Miles and A. M. Huberman, Qualitative Data Analysis: An Expanded Source Book, 2nd ed., Thousand Oaks, CA: Sage, 1994, p. 25.

[38] R. K. Yin, Case Study Research: Design and Methods, 3rd ed., Thousand Oaks, CA: Sage, 2003, p. 13.

[39] J. Gerring, "What is a case study and what is it good for?" American Political Science Review, vol. 98, no. 2, pp. 341-354, 2004.

[40] I. Benbasat, D. K. Goldstein, and M. Mead, "The case research strategy in studies of information systems," MIS Quarterly, vol. 11, no. 3, pp. 369-386, 1987.

[41] J. W. Creswell, Qualitative Inquiry and Research Design: Choosing Among Five Traditions, London: Sage, 1998.

[42] K. M. Eisenhardt, "Building theories from case study research," The Academy of Management Review, vol. 14, no. 4, pp. 532-550, 1989.

[43] G. Guest, E. E. Namey, and M. L. Mitchell, Collecting Qualitative Data: A Field Manual for Applied Research, Thousand Oaks, CA: Sage, 2013.

[44] H. Mariampolski, Qualitative Market Research: A Comprehensive Guide, Thousand Oaks, CA: Sage, 2001.

[45] J. H. Adams, F. M. Khoja, and R. Kauffman, "An empirical study of buyer-supplier relationships within small business organizations," Journal of Small Business Management, vol. 50, no. 1, pp. 20-40, 2012.

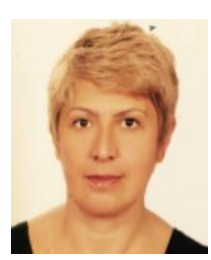

Bahtışen Kavak was born in Artvin, Turkey. She has received $\mathrm{MS}$ and $\mathrm{PhD}$ degrees in business administration from Hacettepe University, Ankara, Turkey. She has been interested in marketing research, industrial marketing, international marketing and marketing models.

She is working as a professor of Marketing at Hacettepe University in Ankara, Turkey.

Prof. Kavak is the president of Marketing and Marketing Research Association (PPAD).

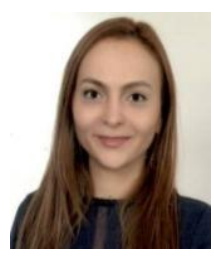

Niray Tunçel was born in Ankara, Turkey. She has received her master degree of marketing in 2011 at Bahçeşehir University in Istanbul. She is doing her $\mathrm{PhD}$ at Hacettepe University in Ankara. She has an interest in the field of marketing research, industrial marketing and consumer ethics.

She works as a research assistant at Hacettepe University in Ankara, Turkey.

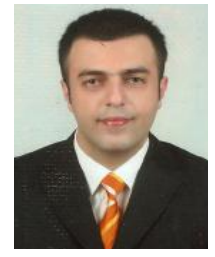

Hüseyin E. Özyörük was born in Aydın, Turkey. He has received his master degree of marketing in 2012 from Hacettepe University. Now, he continues his PhD in the same university. Mr. Özyörük has an interest in the field of marketing research, consumer behavior and industrial marketing.

$\mathrm{He}$ is a full-time lecturer at University of Turkish Aeronautical Association in Ankara, Turkey. 